\title{
THE NATURAL BEHAVIOR OF DROSERA: SUNDEWS DO NOT CATCH INSECTS ON PURPOSE
}

\author{
Polina A. VolKova $\bullet$ Moscow State University • Biological Department • Vorobyevy Gory \\ 119899・Moscow・Russian Federation・avolkov@orc.ru \\ AleXey B. ShIPUNOv • Marine Biological Laboratory • Woods Hole, MA $02543 \bullet$ USA • \\ ashipunov@eol.org
}

Keywords: carnivory: Drosera anglica, D. rotundifolia - field studies: Drosera anglica, D. rotundifolia.

\begin{abstract}
The trapping behavior of carnivorous plants has attracted attention of naturalists for almost two centuries. With the most observations made in laboratories, the behavior of sundew in situ has not been studied enough. We observed Drosera leaf behavior in natural habitats with non-manipulative technique. Three leaf characteristics for two species $(D$. rotundifolia $\mathrm{L}$. and $D$. anglica Huds.) from two regions (6 plants with 30 leaves) were continuously observed during 196 hours. Our observations show that changes of the leaf characteristics of two sundew species in nature are almost casual and likely only corrected by external factors such as relative air humidity and presence of fresh prey ("semi-accidental feeding"). We consider trapping leaves of the two studied Drosera species as transitional structures between active and passive fly-paper traps.
\end{abstract}

\section{Introduction}

The origin and evolution of carnivory is an important and challenging topic in evolutionary ecology (Benzing 1987). However, the origin of carnivory can hardly be studied in animals since this group is likely ancestrally carnivorous (Nielsen 1995). Carnivorous fungi and plants are more applicable for that research. Among the carnivorous plants, sundews (Drosera, Droseraceae) represent an interesting example where, according to experimental data and morphology of some species, both active active and passive prey catching are possible (Juniper et al. 1989).

Most of the research of sundew behavior have been done in laboratories, from the early studies (Kellerman \& Raumer 1878; Busgen 1883) to those conducted in recent times. Experiments usually show that, for some species of sundews, if prey provides sufficient stimulation, all leaf tentacles bend inwards and cover the prey with an enzyme-containing slime. Upon stimulation with the prey, there is a (1) rapid movement of tentacles in the first 10-30 seconds after touching and (2) slow movement by tentacles that were not at first in contact with prey. This slow movement is observed within first hour after initial contact (Hooker 1916). Juniper et al. (1989) state that sundews also secrete a slime just as the prey is captured. After the initial slime secretion, the edge of the leaf blade slowly bends and covers the captured prey. When the digestion process has ended, the leaf blade unwraps, the tentacles straighten and the slime dries (Hooker 1916).

Unfortunately, only several uncoordinated short observations on sundews (Treat 1873; Canby 1874) were conducted in natural habitats. Therefore, the differences between laboratory, artificial conditions, and conditions in situ may affect the observations. For example, factors such as weather (Gomez 1998), edaphic conditions, prey amount available, type of prey, and kleptoparasitism by ants (Thum 1989a) cannot properly be taken into account in the indoor experiments.

Several observational strategies are available for outdoor experiments. We choose the most nonmanipulative one which is referred below as "continuous observations". The team of observers recorded 
several parameters every 30 or $40 \mathrm{~min}$. All watchers were trained to make consistent observations. The first review of results from one species (D. rotundifolia) already suggested that the in situ natural behavior of sundews may be radically different from laboratory behavior (Volkova \& Shipunov 2005). However, at that time we did not process our data statistically, and all observations were restricted to one species.

Different sundew species may differ in feeding behavior. As an example, significant interspecific differences of prey amount that remained on the leaf in 24 hours were revealed in the field experiments (Thum 1988, 1989a,b) with artificial feeding of trapping leaves of D. rotundifolia and long-leaved $D$. intermedia Hayne. Mire ants carry away about two thirds of prey from trapping leaves of $D$. rotundifolia, while prey on the leaves of $D$. intermedia remain almost untouched (Thum 1989b). Drosera rotundifolia is reported to catch three times more prey than $D$. intermedia (Thum 1989a,b). In the north of European Russia, D. rotundifolia grows together with $D$. anglica, another long-leaved sundew species that is similar to D. intermedia both morphologically and ecologically (Webb 1993). Therefore, D. anglica seems to be a good choice for expanding our methods to a larger number of species. We also decided to process our data in a much more detailed way than in our previous work (Volkova \& Shipunov 2005).

\section{Materials and Methods}

To expand the taxonomic coverage of our research, we observed plants of $D$. anglica in natural habitats in Loukhi district of Karelia republic (Northern Karelia, European Russia) on July 16-18, 2005. Plants were growing on the Sphagnum mire on the shore of an unnamed lake (N66 ${ }^{\circ}$ $18.5^{\prime}, \mathrm{E} 33^{\circ} 07.5^{\prime}$ ), and were chosen randomly from a typical population. Each of two chosen plants possessed 7 trapping leaves, therefore there were 14 observational units. Continuous observations for these two plants lasted for 52 hours. At 40 minute intervals we recorded (1) secretion degree, (2) bending degree of marginal tentacles, and (3) shape of each leaf (Volkova \& Shipunov 2005; see also Table 1). We also counted the number of prey units on the leaf blade and measured relative air humidity with a common digital psychrometer located nearby.

Observation in situ is usually a challenge. In particular, we did not use video cameras since it is hard to organize work with cameras in a non-threatening way. Instead, we employed teams of observers. To avoid problems involved with human observers, each team was trained to reach the satisfactory level of consistency. All teams employed in 2000, 2002, and 2005 were led by the same supervisors who controlled quality of observations. The scales (Table 1) were designed to be simple enough, which eased the learning curve.

For the analysis, we also used data from our observations on D. rotundifolia (Volkova \& Shipunov 2005). These observations were performed in North Karelia (nearby location) in 2000, and in Tver region (Middle Russia) in 2002. In all, 4 plants and 16 observational units were observed. Observations in North Karelia and in Tver region continued for 72 hours each (once in approximately $40 \mathrm{~min}$ and once in $30 \mathrm{~min}$ respectively).

For each leaf in the D. anglica and D. rotundifolia data, we created graphs of changes of all the three leaf characteristics during the observation time. The most typical graphs are presented in Figures 1-3.

All data were analyzed mostly with non-parametric statistical methods. Leaf reaction to the prey was examined using Wilcoxon tests, comparing the characters of leaf in the moment of prey capture and in the given time shift $(0.5,1,2$, and 3 hours). Wilcoxon tests were also employed to compare the observed leaf behaviour with the expected behaviour, predicted from the literature data of indoor experiments (Hooker 1916; Juniper et al. 1989), and to compare leaves with the absence of prey with leaves having the prey after $1 \mathrm{~h}$ interval. Concordance of changes of different characters of the given leaf as well as concordance between leaves of one plant was checked with Spearman correlation test. This test was also employed to reveal the dependence of different leaf characters on air humidity. Chi-square tests were used to understand the significance of the amount of leaves with characteristics unexpected from the literature. Finally, ANOVA were used for revealing the relationship between leaf characteristics and air humidity, for analysis of the dependence between time shift and leaf characteristics, and for the analysis of coordination between different leaves of the same plant. 
(a) Drosera rotundifolia, Northern Karelia
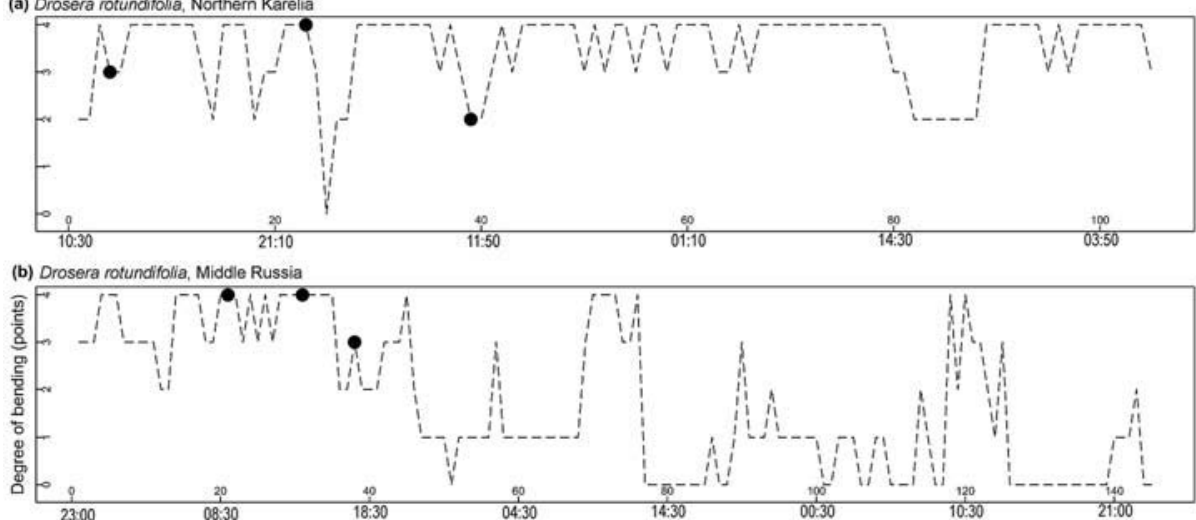

(c) Drosera anglica, Northern Karelia

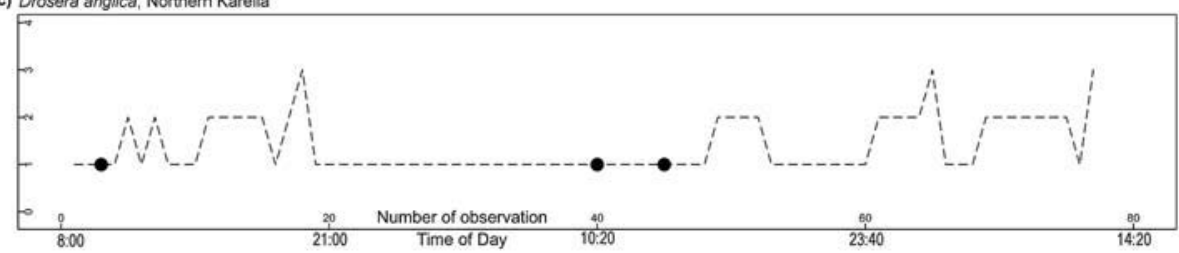

Figure 1: Changes in the degree of bending of marginal tentacles of model Drosera leaves. The times of arrival of the fresh insect on the leaf blade are shown with filled circles.

(a) Drosera rotundifolia, Northern Karelia

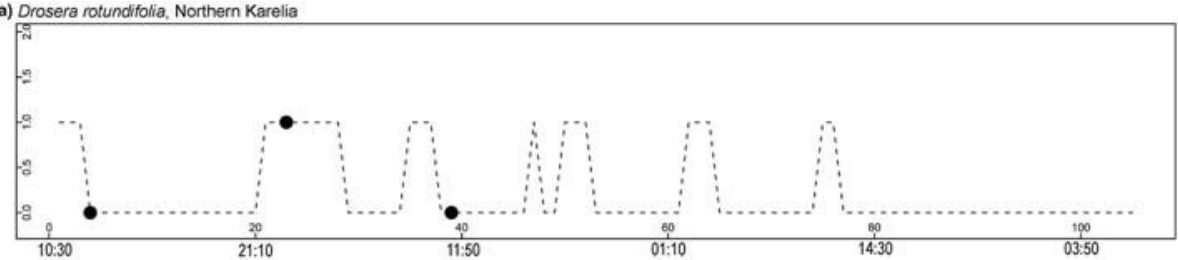

(b) Drosera rotundifolia, Middle Russia

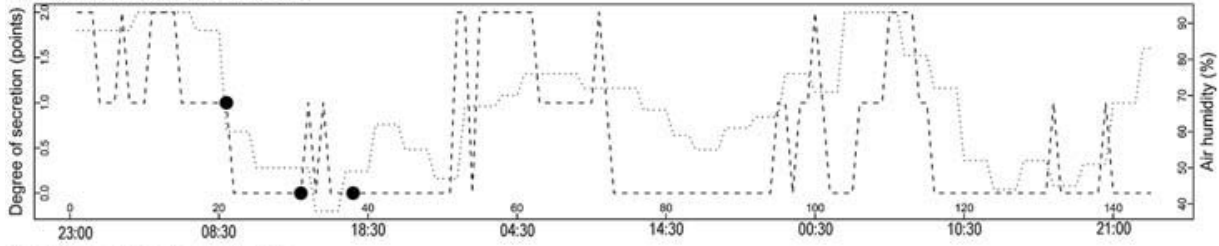

(c) Drosera anglica, Northern Karelia

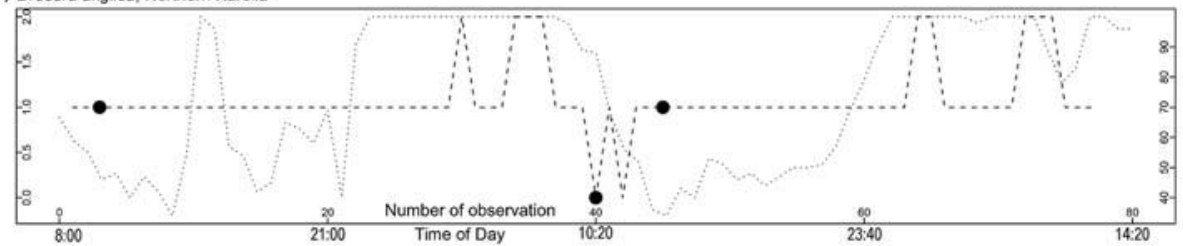

Figure 2: Changes in the degree of secretion of model Drosera leaves, compared with changes of relative air humidity. Relative air humidity (right Y-axis) is shown with the dotted line (not available for D. rotundifolia in Northern Karelia). The times of arrival of the fresh insect on the leaf blade are shown with filled circles. 

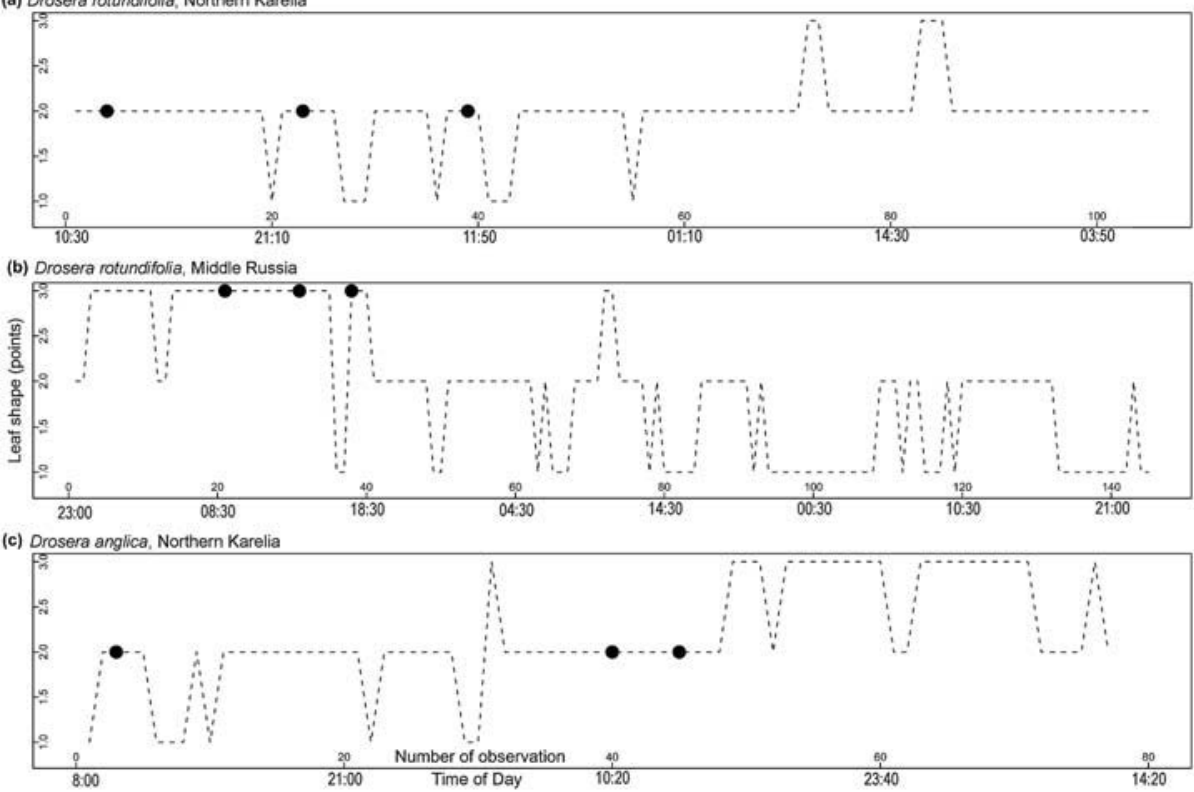

Figure 3: Changes in the shape of the model Drosera leaves. The times of arrival of the fresh insect on the leaf blade are shown with filled circles.

Differences between feeding strategies of $D$. rotundifolia and $D$. anglica, revealed by visual inspection of our data (Table 1), were illustrated with PCA (principal component analysis) of averaged behavior for all three species/region groups plus the "ideal" sundew (imaginary plant with maximal values of leaves characteristics in 1 hour after prey catching).

For statistical analyses and graph creation, $\mathrm{R}$ environment for statistical computing was used (R Development Core Team 2007).

Results

A significant number of trapping leaves did not react to the prey in one hour: from $52 \%$ for D. rotundifolia in North Karelia to $29 \%$ for the same species in Tver region (45\% for pooled data). These proportions were significantly different from the expectation of $95 \%$ change (Chi-square test $\mathrm{p}<<0.05$ for all four cases). In next two hours, leaf conditions did not change significantly: ANOVA analysis for $0.5,1,2$, and 3 hour time shifts did not reveal any significant dependence between time and leaf characteristics (in all three cases $\mathrm{p}>>0.1$ ). In general, there were no significant differences between leaf condition at the moment of prey capture and in one hour later (Wilcoxon $\mathrm{p}>>0.1$ for all three leaf characteristics). Only degree of secretion, and only for plants from North Karelia demonstrated some significant differences (Wilcoxon $\mathrm{p}<<0.05$ for both $D$. anglica and $D$. rotundifolia from this region). At the same time, there was an evident relation between the degree of secretion and relative air humidity (see Figures 2 and 4; Spearman $\rho=0.37$, $\mathrm{p}<<0.05$; ANOVA $\mathrm{p}<<0.05)$. Degree of bending and shape were correlated with humidity to a much lower extent (Spearman $\rho<0.1$ in both cases).

Quite often the behavior of leaves was different from that usually discussed in the literature (see Figures 1-3), or "ideal behavior" (to imitate this behavior, we used maximal values of leaf characteristics). As an example, all the leaf characters in 0.5-3 hours after prey capture differed significantly from "ideal" values (Wilcoxon $\mathrm{p}<<0.01$ for all leaf characteristics). 


\begin{tabular}{|l|l|}
\hline \multicolumn{1}{|c|}{ Leaf characteristics } & \multicolumn{1}{|c|}{ Scores } \\
\hline Secretion degree & $\begin{array}{l}0 \text { - poor, the leaf is almost dry } \\
1-\text { medium } \\
2-\text { high, droplets are well-formed }\end{array}$ \\
\hline Leaf shape & 1 - leaf is almost flat \\
& 2 - leaf is almost flexed \\
& 3 - leaf is almost bent \\
\hline Degree of bending & 1 - no or few bent tentacles \\
& $2-$ approximately half of the tentacles are bent \\
& 3 - all or almost all tentacles are bent \\
\hline
\end{tabular}

Table 1: Leaf characters observed.

Characteristics of leaves without prey did not differ significantly from characteristics of leaves that caught prey 1 hour ago (Wilcoxon $\mathrm{p}>0.1$ ) for all cases except degree of secretion for North Karelian plants (Wilcoxon $\mathrm{p}<<0.05$ ). In addition, leaves without prey often had the "wrong" condition: more than $44 \%$ of them have all three characteristics that deviated from condition "by default" (Chi-square $\mathrm{p}<<0.05$ ).

Changes of different types were not correlated - averaged coefficients of correlation between all the three leaf characters were lower than 0.33 (mean correlation 0.06). The correlation in behavior of all leaves from the same plant was low (Spearman $\rho=0.25$ ), but for bending and secretion of leaves belonging to $D$. rotundifolia from Tver region, values of correlation were higher than 0.4 and significant. Consequently, ANOVA analysis of correlation between years revealed a significant difference $(\mathrm{p}<<0.05)$ whereas no differences in correlation coefficients were revealed from comparison of different characteristics from pooled data (ANOVA $\mathrm{p} \gg>0.1$ ) and from comparison of different plants observed in the same year (Wilcoxon paired signed rank test $\mathrm{p}>>0.1$ ).

For $D$. anglica the number of insects caught varied from 0 to 1.4 (0.6 in average) per leaf in a day, while $D$. rotundifolia trapped from 0 to 0.7 insects ( 0.3 in average) in the Northern Karelia, and from 0 to 3.0 (1.0 in average) in the Middle Russia. PCA analysis of one hour behavior for all three species/region groups revealed that $D$. rotundifolia plants from Moscow region behaved similar to $D$. anglica and D. rotundifolia from North Karelia. All three observations were distant from the "ideal" plant which differed from plants observed in nature by all three leaf characteristics. Drosera rotundifolia plants from North Karelia demonstrated more developed bending whereas $D$. anglica demonstrated more developed secretion (see Figure 5).

\section{Discussion}

In all, our statistical analysis support the conclusion stated in our previous paper (Volkova \& Shipunov 2005): secretion, leaf curving, and tentacle bending do not depend on prey capture, and secretion is probably regulated by relative humidity. Our results do not let us speculate about inconsistency between field and laboratory data. One possible reason could be that in artificial conditions sundew plants were simply overfed. Nevertheless, this inconsistency emphasizes the necessity of further investigation of trapping behavior of sundews.

The analysis also showed that differences between regions and between $D$. anglica and $D$. rotundifolia are almost equal. Despite the slightly different tactics, there is much more in common between the two studied Drosera species. This similarity could be caused by close genetic relationships between the two species (Rivadavia et al. 2003). The absence of correlation between the behavior of trapping leaves and presence of prey let us to consider sundew trapping leaves as a structure transitional between active and passive flypaper traps, whereas the common opinion con- 
siders them as active flypaper traps (see, for example, Williams 1976; Heubl et al. 2006). Our data also support the recent hypothesis on the facultative role of carnivory in the carnivorous plants (Dore \& Maham 1969; Small et al. 1977; Stewart \& Nilsen 1992; Ellison \& Gotelli 2001).

In general, it is possible to distinguish two main stages in every feeding process (Hardys et al. 1990): "catching" (binding of food with the feeding organ) and "digesting" (absorption of food). There are transitions between "poor catchers and digesters" as protocarnivorous plants (Spomer 1999) and "perfect catchers and digesters" as carnivorous plants with snap-traps (Heubl et al. 2006). Some primitive animals like Hydra, or Eleutheria appear to be "non-perfect catchers", but "perfect digesters" (Lasker et al. 1982; Hardys et al. 1990). According to this classification, the two studied Drosera species in the Middle and Northern European Russia, being "non-perfect catchers and digesters", have a separate feeding type which can be named as "semi-accidental feeding".

In both non-animal carnivores, nematodetrapping fungi, and carnivorous plants, evolution of feeding structures have many common features (Mueller et al. 2004; Li et al. 2005; Heubl et al. 2006). In particular, primitive passive traps (passive fly-paper and adhesive knobs, respectively) evolved in two directions: perfect passive traps (pitfall traps and threedimensional networks) and perfect active traps (snap and active flypaper traps and constricting rings). Since the flypaper traps of Drosera were likely derived from the ancestral passive traps, we can suppose that transition from passive to active traps happened within the Drosera genus, causing our two species with the semiaccidental feeding to be in the middle of this transition.

Acknowledgements: Data were collected during White Sea expeditions of Moscow South-West High School led by Dr. S. Glagolev. We thank Yu. Bykov, M. Lyovina, and K. Markvichyova for their essential help in the field observations and Dr. L. Adamec for his valuable comments on the manuscript. No permits were required to conduct the research described in this paper.

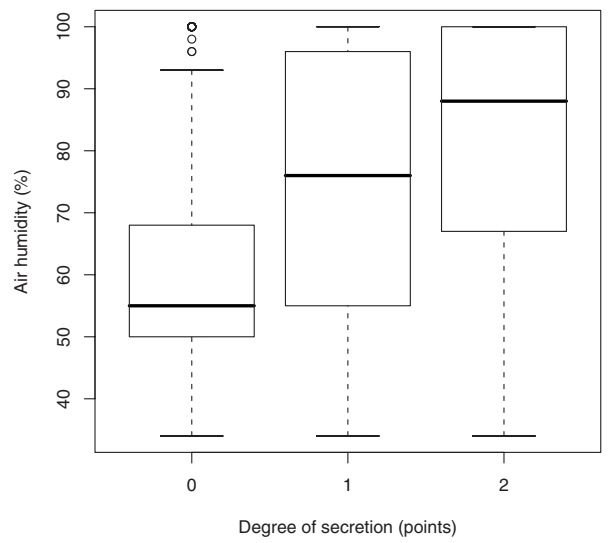

Figure 4: Box plot demonstrating the dependence between air humidity and degree of secretion (for all data).

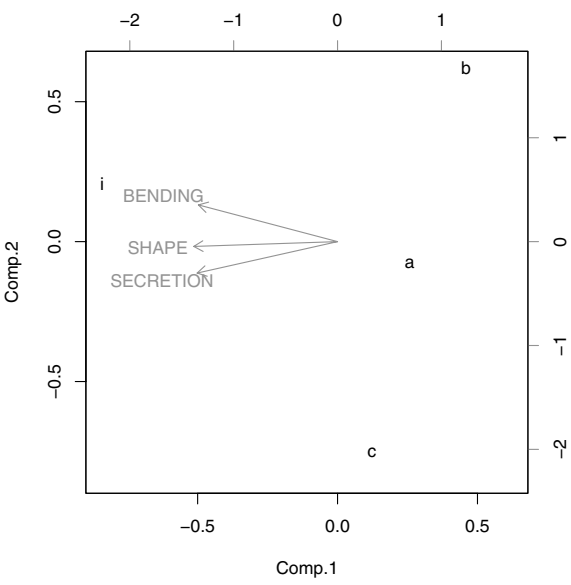

Figure 5: Biplot of the principal component analysis (PCA). Arrows represent character loading, points belong to the averaged one-hour behavior of each observed species/region, plus "ideal" sundew (imaginary plant with maximal values of leaves characteristics); a: D. rotundifolia, Northern Karelia; b: D. rotundifolia, Middle Russia; c: D. anglica, Northern Karelia; i: "ideal” plant. 


\section{References}

Benzing, D.H. 1987. The origin and rarity of botanical carnivory. Trends in Ecology \& Evolution 2: 364-369. 1987.

Busgen, M. 1883. Die Bedeutung des Insektenfangs für Drosera rotundifolia. Bot. Zeitung 41: 569-577. Canby W.M. 1874. Observations on Drosera filiformis. Am. Nat. 8: 396-397.

Dore, S.R., and Maham, R.H.J. 1969. Studies on growth and flowering in axenic cultures of insectivorous plants. Phytomorphology 19: 363.

Ellison, A.M., and Gotelli, N.J. 2001. Evolutionary ecology of carnivorous plants. Trends in Ecol. and Evol. 16 (11): 623-629.

Gomez, L.D. 1998. Natural history and occurrence of the "insectivorous plant" Drosera capillaris (Droseraceae) in Costa Rica. Revista de Biologia Tropical 46: 1033-1037.

Hardys, H., Schierwater, B., and Mrowka, W. 1990. The feeding behavior of a semi-sessile hydromedusa and how it is affected by the mode of reproduction. Animal Behavior 40: 935-944.

Heubl, G., Bringmann, G., and Meimberg, H. 2006. Molecular phylogeny and character evolution of carnivorous plant families in Caryophylalles - revisited. Plant Biology (Stuttg.) 8 (6): 821-830.

Hooker, H.D. 1916. Physiological observations on Drosera rotundifolia. Bull. Torr. Bot. Club 43(1): 1-27.

Juniper, B.E., Robins, R.J., and Joel, D.M. 1989. The carnivorous plants. London. 353 p.

Kellerman, C., and Rauner, E. 1878. Vegetations versache an Drosera rotundifolia mit und ohne Fleischfütterung. Bot. Zeitung 36: 209-218.

Lasker, H.R., Syron, J.A., and Clayton, W.S. 1982. The feeding response of Hydra viridis: effects of prey density on capture rates. Biol. Bull. 162: 290-298.

Li, Y., Hyde, K.D., Jeewon, R., Cai, L., Vijaykrishna, D., and Zhang, K. 2005. Phylogenetics and evolution of nematode-trapping fungi (Orbiliales) estimated from nuclear and protein coding genes. Mycologia 97: 1034-1046.

Mueller, K., Borsch, T., Legendre, L., Porembski, S., Theisen, I., and Barthlott, W. 2004. Evolution of carnivory in Lentibulariaceae and the Lamiales. Plant Biol. (Stuttg.) 6(4): 477-90.

Nielsen, C. 1995. Animal evolution. Oxford University Press, Oxford.

R Development Core Team. 2007. R: A language and environment for statistical computing. R Foundation for Statistical Computing, Vienna.

Rivadavia F., Kondo K., Kato M., and Hasebe M. 2003. Phylogeny of sundews, Drosera (Droseraceae), based on chloroplast $r b c L$ and nuclear $18 \mathrm{~S}$ ribosomal DNA sequences. Am. J. Bot. 90 (1): 123-130.

Small, J.G.C., Onraet, A., Grierson, D.S., and Reynolds, G. 1977. Studies on insect-free growth, development and nitrate-assimilating enzymes of Drosera aliciae R.Hamet. New Phytol. 79: 127-133.

Spomer, G.G. 1999. Evidence of protocarnivorous capabilities in Geranium viscosissimum and Potentilla arguta and other sticky plants. Int. Journ. Pl. Sci. 160: 98-101.

Stewart, C.N., and Nilsen, E.T. 1992. Drosera rotundifolia growth and nutrition in a natural population with special reference to the significance of insectivory. Can. J. Bot. 70(7): 1409-1416.

Thum, M. 1988. The significance of carnivory for the fitness of Drosera in its natural habitat 1 . The reactions of $D$. intermedia and $D$. rotundifolia to supplementary feeding. Oecologia 75: 472-480.

Thum, M. 1989a. The significance of opportunistic predators for the sympatric carnivorous plant species Drosera intermedia and Drosera rotundifolia. Oecologia 81: 397-400.

Thum, M. 1989b. The significance of carnivory for the fitness of Drosera in its natural habitat 2 . The amount of captured prey and its effect on Drosera intermedia and Drosera rotundifolia. Oecologia 81: 401-411.

Treat, M. 1873. Observations on the sundew. Am. Nat. 7: 705-708.

Volkova, P.A., and Shipunov, A.B. 2005. The behavior of Drosera rotundifolia L. (Droseraceae) trapping leaves in natural habitats. Carniv. Pl. Newslett. 34: 7-15.

Webb, D.A. 1993. Drosera L. In: Tutin, T., Heywood, V., Burges, A., Valentine, D. (eds.) Flora Europaea. Vol. 1. Ed. 2. University Press, Cambridge, pp 421-422.

Williams, S.E. 1976. Comparative sensory physiology of the Droseraceae - the evolution of plant sensory system. Proceedings of the American Philosophical Society 120: 187-204. 